\title{
Analysis of the Mechanism of Loss of Trophic Factor Dependence Associated with Neuronal Maturation: A Phenotype Indistinguishable from Bax Deletion
}

\author{
Rachael M. Easton, ${ }^{1,2}$ Thomas L. Deckwerth, ${ }^{1,2}$ Alexander Sh. Parsadanian, ${ }^{1}$ and Eugene M. Johnson Jr ${ }^{1,2}$ \\ Departments of ${ }^{1}$ Neurology and ${ }^{2}$ Molecular Biology and Pharmacology, Washington University School of Medicine, \\ Saint Louis, Missouri 63110
}

\begin{abstract}
During development, sympathetic neurons are critically dependent on nerve growth factor (NGF) for survival. Neurons isolated from the superior cervical ganglia (SCG) of embryonic rodents and maintained for 1 week in vitro undergo programmed cell death in response to NGF deprivation. As the cells mature in vitro and in vivo, however, these neurons develop a resistance to NGF deprivation and become much less acutely dependent on NGF for survival. Using an in vitro model of neuronal maturation, we confirmed that SCG neurons maintained in culture for 3-4 weeks did not experience a dramatic loss in viability after NGF removal, yet they did undergo the initial biochemical and genetic changes elicited by NGF deprivation of young neurons. NGF deprivation of mature neurons produced rapid decreases in glucose uptake and protein and RNA synthesis rates, increased phosphorylation of C-Jun, and an increase in c-jun mRNA. Mature neurons, however, experienced a block in the
\end{abstract}

cell death program before the final stages of the pathway activated in young neurons, which includes the induction of c-fos mRNA and characteristic apoptotic nuclear changes. This maturation-induced block was indistinguishable by these criteria from the block produced by Bax deficiency. Expression of $B a x$ in mature neurons restored the apoptotic pathway, such that after NGF removal, Bax-overexpressing mature neurons resumed the apoptotic program, including the induction of c-Fos and passage through a caspase checkpoint. Thus, a block in the apoptotic program at or near the BAX checkpoint accounts for the decreased dependence of mature neurons on neurotrophic factor to maintain survival.

Key words: neuronal maturation; trophic factor dependence; neuronal cell death; BAX; gene expression; neuronal metabolism
During development, naturally occurring cell death refines the nervous system. This developmental cell death can be simulated in vitro by using cultures of embryonic sympathetic neurons. These neurons are maintained in culture in the presence of nerve growth factor (NGF) and after 1 week will undergo programmed cell death in vitro after removal of this trophic factor. After $\geq 3$ weeks in culture with NGF, however, these neurons become largely resistant to NGF deprivation (Lazarus et al., 1976; Chun and Patterson, 1977). This maturation mimics the loss of acute trophic factor dependence in vivo (Angeletti et al., 1971; Bjerre et al., 1975; Goedert et al., 1978; Otten et al., 1979). An increased resistance to trophic factor withdrawal has been described for a number of neuronal populations and may be an important protective mechanism for maintenance of the nervous system (Snider et al., 1992).

Preceding death, young sympathetic neurons undergo a series of events, including a rapid decrease in metabolism (Deckwerth and Johnson, 1993), the phosphorylation of c-Jun (T. L. Deckwerth, R. M. Easton, C. M. Knudson, S. J. Korsmeyer, and E. M. Johnson Jr, unpublished data), and both an early and late wave of gene induction represented by c-jun and c-fos, respectively (Estus

Received Aug. 7, 1997; revised Sept. 24, 1997; accepted Oct. 6, 1997.

This work was supported by National Institutes of Health Grants NS 24679 and AG 12947. We thank Mohanish Deshmukh, Timothy M. Miller, and Patricia A. Osborne for critical evaluation of this manuscript.

Correspondence should be addressed to Eugene M. Johnson Jr, Washington University School of Medicine, Department of Molecular Biology and Pharmacology, 660 South Euclid Avenue, Box 8103, St. Louis, MO 63110-1031.

Copyright (C) 1997 Society for Neuroscience $\quad 0270-6474 / 97 / 179656-11 \$ 05.00 / 0$ et al., 1994). After these metabolic and genetic changes, a caspase inhibitor, Boc-Asp(OMe)-FMK (BAF), halts the apoptotic pathway (Deshmukh et al., 1996).

In addition to caspases, members of the BCL2 family are important modulators of this cell death pathway. The BCL2 family includes both proapoptotic and antiapoptotic members that enhance (Farrow et al., 1995; Vekrellis et al., 1997) or retard (Garcia et al., 1992; Gonzalez-Garcia et al., 1995; Greenlund et al., 1995) cell death. In the complete absence of the proapoptotic family member BAX, sympathetic neurons do not die after NGF deprivation, demonstrating that BAX levels not only modulate the kinetics of neuronal death, but that BAX is required for neuronal cell death after trophic factor removal (Deckwerth et al., 1996). Analysis of the metabolic and genetic events in Baxdeficient neurons defined a BAX checkpoint downstream of the early metabolic changes, c-Jun phosphorylation and elevation of c-jun levels, but upstream of c-fos mRNA induction and caspase activation (Miller et al., 1997) (Deckwerth, Easton, Knudson, Korsmeyer, and Johnson, unpublished data).

In this study, we examined the point at which the block occurs in the events associated with programmed cell death that provides the mature neuron with an increased resistance to trophic factor deprivation. To this end, we analyzed the metabolic and genetic events that occur in mature sympathetic neurons (3-4 weeks in vitro) in response to NGF deprivation and compared the timing of events with that described for wild-type, Bax-deficient (Deckwerth, Easton, Knudson, Korsmeyer, and Johnson, unpublished data), and caspase inhibitor-treated young neurons (Deshmukh et al., 1996). We found that mature neurons recapitulated the initial 
stages of the cell death pathway of NGF-deprived young neurons and arrested at a point indistinguishable from that produced by Bax deficiency. Moreover, Bax overexpression restored trophic factor dependence and allowed the mature neurons to resume the apoptotic pathway after NGF withdrawal.

\section{MATERIALS AND METHODS}

\section{Materials}

Reagents were purchased from Sigma (St. Louis, MO) unless otherwise stated. Timed-pregnant Sprague Dawley rats were obtained from Harlan Sprague Dawley (Indianapolis, IN). Collagenase and trypsin were purchased from Worthington (Freehold, NJ). AM0 medium consisted of Eagle's MEM with Earle's salts (Life Technologies, Gaithersburg, MD) supplemented with $10 \%$ fetal bovine serum (Sigma), $100 \mathrm{U} / \mathrm{ml}$ penicillin, $100 \mu \mathrm{g} / \mathrm{ml}$ streptomycin, $1.4 \mathrm{~mm}$ L-glutamine, $20 \mu \mathrm{M}$ fluorodeoxyuridine, and $20 \mu \mathrm{M}$ uridine. AM50 medium consisted of AM0 medium with 50 $\mathrm{ng} / \mathrm{ml}$ mouse 2.5S NGF (Harlan Bioproducts, Indianapolis, IN).

\section{Cell culture}

Primary sympathetic neuronal cultures were established from superior cervical ganglia of embryonic day 21 rats by using a modification of a previously described method (Johnson and Argiro, 1983). After dissection, ganglia were treated with $1 \mathrm{mg} / \mathrm{ml}$ collagenase for $30 \mathrm{~min}$ at $37^{\circ} \mathrm{C}$ followed by $2.5 \mathrm{mg} / \mathrm{ml}$ trypsin for $30 \mathrm{~min}$ at $37^{\circ} \mathrm{C}$. The ganglia were then triturated with a flame-polished Pasteur pipette and filtered through a size 3-20/14 Nitex filter (Tetko Inc., Elmsford, NY). The number of viable cells was determined by trypan blue exclusion, and the cells were plated in a drop of AM50 on air-dried, ammoniated, collagen-coated tissue culture dishes. For microinjection and immunohistochemistry, 2000-3000 cells were plated on $35 \mathrm{~mm}$ dishes (Corning, Corning, NY) and two-well chamber slides (Nunc, Naperville, IL), respectively. For RNA synthesis, glucose uptake, and cDNA preparation, $15,000-20,000$ cells were plated on 24-well (Costar, Cambridge, MA), four-well (Nunc), and $35 \mathrm{~mm}$ tissue culture dishes, respectively. For Western blot analysis, $\sim 150,000$ cells were plated in $35 \mathrm{~mm}$ tissue culture dishes. After allowing the cells to attach for $1-3 \mathrm{hr}$ at $37^{\circ} \mathrm{C}$, additional AM50 was added to the wells. For long-term cultures, the medium was removed and replaced with fresh AM50 medium every $4 \mathrm{~d}$. After the first week in culture, cell numbers declined steadily with a $6 \%$ decrease per week, so mature cultures that were maintained 3.5 weeks in vitro contained $\sim 85 \%$ of the neurons present in the young SCG cultures (1 week in vitro).

\section{NGF deprivation}

Sympathetic neuronal cultures were deprived of NGF by rinsing once with AM0, followed by the addition of AM0 containing goat anti-2.5S mouse NGF antiserum, a neutralizing antibody against NGF (anti-NGF) (Ruit et al., 1990). Control cultures were treated similarly; their medium was replaced with fresh AM50 at the time of deprivation to control for any effect of the medium exchange on metabolic parameters or immunohistochemical staining.

\section{Viability measurements}

Viability of sympathetic neurons was quantified after fixation of the cultures with $4 \%$ paraformaldehyde and staining with crystal violet (Deckwerth and Johnson, 1993) or assessed qualitatively by staining with calcein AM (Molecular Probes, Eugene, OR).

\section{Cell diameter}

Soma diameters were determined from photomicrographs of living neuronal cultures as described previously (Deckwerth et al., 1996).

\section{Metabolic parameters}

Metabolic parameters were measured by using the procedures described by Deckwerth and Johnson (1993) with slight modifications. The metabolic rates were linear with respect to time during the measurement period (data not shown).

Total neuronal protein. After NGF deprivation, neuronal cultures were lysed into $200 \mu \mathrm{l}$ of reagent A of the BCA protein assay from Pierce (Rockford, IL). The absorbance of the $\mathrm{Cu}^{+}-\mathrm{BCA}$ complex was read with a Titertek Multiscan MC 96-well plate reader, and the protein concentration was determined from an internal BSA standard.
Rate of protein synthesis. After deprivation, neurons were labeled for 4 hr at $37^{\circ} \mathrm{C}$ with $10 \mu \mathrm{Ci} / \mathrm{ml}\left[{ }^{35} \mathrm{~S}\right]-\mathrm{L}$-methionine $(>1000 \mathrm{Ci} / \mathrm{mmol}$; ICN Biochemicals, Costa Mesa, CA) in modified AM0 medium containing 10 $\mu \mathrm{M}$ unlabeled L-methionine. Cultures were washed once with medium and then lysed in $500 \mu \mathrm{l}$ of $0.5 \%$ SDS, $1 \mathrm{~mm}$ EDTA, and $10 \mathrm{~mm}$ Tris- $\mathrm{HCl}$, $\mathrm{pH}$ 7.5. The protein was precipitated with $10 \%$ trichloroacetic acid (TCA) on ice. The precipitate was then filtered through $0.45 \mu \mathrm{m}$ nitrocellulose and washed with cold $10 \%$ TCA, and its radioactivity was measured with a liquid scintillation counter (Beckman, Fullerton, CA).

Rate of RNA synthesis. After deprivation, cultures were washed twice with modified AM0 medium lacking uridine and fluorodeoxyuridine and labeled with $10 \mu \mathrm{Ci} / \mathrm{ml}\left[5,6-{ }^{3} \mathrm{H}\right]$ uridine (44 Ci/mmol; ICN Biochemicals) in modified AM0 or AM50 medium lacking uridine and fluorodeoxyuridine for $4 \mathrm{hr}$ at $37^{\circ} \mathrm{C}$. The cultures were washed three times with PBS and lysed with $500 \mu \mathrm{l}$ of $0.5 \% \mathrm{~N}$-lauroylsarcosine, $1 \mathrm{~mm}$ EDTA, and $10 \mathrm{~mm}$ Tris- $\mathrm{HCl}, \mathrm{pH}$ 7.5. The RNA was precipitated with cold $10 \%$ TCA and $1 \%$ sodium pyrophosphate on ice for $1 \mathrm{hr}$. The precipitate was collected by filtration through $0.45 \mu \mathrm{m}$ nitrocellulose and washed twice with cold $10 \%$ TCA and $1 \%$ sodium pyrophosphate, and the radioactivity was measured in a Beckman liquid scintillation counter.

Rate of glucose uptake. At various times after deprivation, neuronal cultures were rinsed with AM0 modified to contain only $500 \mu \mathrm{M}$ Dglucose and labeled with $2.5 \mu \mathrm{Ci} / \mathrm{ml}$ 2-deoxy-D-[1,2- $\left.{ }^{3} \mathrm{H}\right]$ glucose $(30 \mathrm{Ci}$ / mmol; Amersham, Arlington Heights, IL) in modified AMO medium for $10 \mathrm{~min}$ at $37^{\circ} \mathrm{C}$. Cultures were washed three times with PBS containing 1 $\mathrm{mg} / \mathrm{ml} \mathrm{D-glucose}$, lysed in $500 \mu \mathrm{l}$ of $0.5 \% N$-lauroylsarcosine, $1 \mathrm{~mm}$ EDTA, and $10 \mathrm{~mm}$ Tris- $\mathrm{HCl}, \mathrm{pH} 7.5$, and added to liquid scintillation fluid, and radioactivity was determined.

\section{Immunohistochemistry}

Neuronal cultures were washed once with PBS, $\mathrm{pH} 7.4$, before a $30 \mathrm{~min}$ fixation with $4 \%$ paraformaldehyde in PBS at $4^{\circ} \mathrm{C}$. Neuronal cultures were washed three times with TBS $(100 \mathrm{~mm}$ Tris- $\mathrm{HCl}$ and $0.9 \% \mathrm{NaCl}$, $\mathrm{pH}$ 7.6), exposed to blocking solution [TBS containing 5\% goat serum (Sigma) and $0.3 \%$ Triton X-100] for $30 \mathrm{~min}$ at room temperature (RT), and incubated in primary antibody diluted in TBS, $1 \%$ goat serum, and $0.3 \%$ Triton $\mathrm{X}-100$ at $4^{\circ} \mathrm{C}$ overnight. Neuronal cultures were then washed three times with TBS and incubated at $4^{\circ} \mathrm{C}$ overnight in the appropriate secondary antibody diluted in TBS, $1 \%$ goat serum, and $0.3 \%$ Triton $\mathrm{X}-100$. Cultures were washed twice in TBS and stained with $1 \mu \mathrm{g} / \mathrm{ml}$ Hoechst 33258 (Molecular Probes) for $20 \mathrm{~min}$ at RT. After rinsing with TBS, cultures were coverslipped and examined by fluorescence microscopy. For phospho-c-Jun staining, the primary antibody was a rabbit polyclonal anti-phospho-c-Jun (Ser63) antibody (New England Biolabs, Beverly, MA) diluted 1:200, and the secondary antibody was a Cy3conjugated donkey anti-rabbit IgG $(1.5 \mathrm{mg} / \mathrm{ml}$; Jackson ImmunoResearch, West Grove, PA) diluted 1:400. The FLAG-tagged BAX protein was detected with a mouse monoclonal M2 anti-FLAG antibody (3.0 $\mathrm{mg} / \mathrm{ml}$; Eastman Kodak, Rochester, NY) diluted 1:500 followed by a Cy3-conjugated donkey anti-mouse IgG $(0.625 \mathrm{mg} / \mathrm{ml}$; Jackson ImmunoResearch) diluted 1:400. For Fos immunohistochemistry, the primary antibody was the rabbit polyclonal anti-Fos antibody (SC-052; Santa Cruz Biotechnology, Santa Cruz, CA) diluted 1:2000, and the secondary antibody was a Cy3-conjugated donkey anti-rabbit IgG $(1.5 \mathrm{mg} / \mathrm{ml}$; Jackson ImmunoResearch) diluted 1:400.

\section{Reverse transcription-PCR analysis}

Reverse transcription (RT)-PCR analysis of SCG neuronal cultures has been described previously (Estus et al., 1994; Freeman et al., 1994). The rationale and methodology for this procedure have been detailed (Estus, 1997). In summary, mRNA was isolated at specified times after NGF deprivation by using an oligo-dT-cellulose mRNA purification kit (QuickPrep Micro kit; Pharmacia, Piscataway, NJ) according to the manufacturer's instructions. The cell lysates from the young neurons (1 week in vitro) were stored at $-70^{\circ} \mathrm{C}$ until they could be processed in parallel with lysates from NGF-deprived, mature neurons (4 weeks in vitro), which allowed us to compare more accurately the response of the mature neurons after NGF deprivation to the known genetic changes that occur in young neurons. Half of the mRNA was converted into cDNA by reverse transcription using Moloney murine leukemia virus reverse transcriptase and random hexamers $(16 \mu \mathrm{M})$ as primers. For PCR analysis, $1 \%$ of the cDNA was used in a $50 \mu \mathrm{l}$ PCR reaction; half of the PCR reaction was separated on a $10 \%$ polyacrylamide gel, and the PCR product was visualized with a PhosphorImager (Molecular Dynamics, Sunnyvale, CA). No PCR product was amplified when purified mRNA 
was used in the PCR reaction (data not shown). Each gene was tested in two independent time courses. The sequences of PCR products were confirmed by DNA sequencing (Estus et al., 1994; Freeman et al., 1994). The primer sequences for cyclophilin, c-jun, $m k p-1$, c-fos, and fos $B$ have been reported previously (Freeman et al., 1994; Miller and Johnson, 1996).

\section{Construction and injection of the FLAG-Bax construct}

The FLAG epitope (DYKDDDDK) (Hopp et al., 1988) was fused to the $\mathrm{N}$ terminus of Bax by means of synthetic oligonucleotides. The original murine Bax cDNA (generously provided by Dr. Stanley J. Korsmeyer, Washington University, St. Louis, MO) served as the template for a PCR reaction that used a $5^{\prime}$ oligonucleotide containing the sequence for the FLAG tag and an EcoRI site for cloning (5'-GCG AAT TCC ACC ATG GAC TAC AAG GAC GAC GAT GAC AAG GAC GGG TCC GGG GAG CAG-3') and a $3^{\prime}$ oligonucleotide encoding an $X b a \mathrm{I}$ restriction site (5'-GCT CTA GAT CAG CCC ATC TTC TTC CAG-3'). The PCR product was digested with $E c o$ RI and $X b a \mathrm{I}$, separated by agarose gel electrophoresis, purified, and cloned into the pcDNA3 expression vector (Invitrogen, San Diego, CA). In-frame fusion of the FLAG sequence to the murine Bax cDNA was confirmed by DNA sequencing.

For microinjection, sympathetic neurons were switched to Leibovitz's L-15 medium (Life Technologies) containing $100 \mathrm{U} / \mathrm{ml}$ penicillin and 100 $\mu \mathrm{g} / \mathrm{ml}$ streptomycin and co-injected with $25-50 \mu \mathrm{g} / \mathrm{ml}$ pGreenLantern-1 (Life Technologies), a plasmid encoding green fluorescent protein (GFP), and either $100 \mu \mathrm{g} / \mathrm{ml}$ FLAG-Bax construct or $100 \mu \mathrm{g} / \mathrm{ml}$ pcDNA3 (Invitrogen). After injection, cultures were given fresh AM50 medium and incubated overnight at $37^{\circ} \mathrm{C}$. The number of viable injected neurons was determined by counting the number of phase-bright cell bodies that displayed the green fluorescence characteristic of GFP (Chalfie et al., 1994). The experiment was then started by depriving the cultures of NGF, whereas control cultures were maintained in NGF. Twenty-four and $48 \mathrm{hr}$ later, viable, injected neurons were scored by a naive observer.

The marker plasmid expressing GFP allowed the microinjected neurons to be visualized without fixation or staining procedures, thereby permitting individual neurons to be followed longitudinally (Chalfie et al., 1994). Preliminary studies indicated that mature neurons, which survived the microinjection procedure, efficiently expressed GFP over time without affecting their viability. Furthermore, expression of GFP in young neurons does not interfere with the induction of apoptosis after NGF withdrawal (D. J. Creedon, personal communication). Thus, expression of GFP was used to quantify neurons over time after microinjection and the subsequent NGF deprivation.

\section{Western blot analysis of $B A X$ and $B C L-X$ protein}

Neuronal cultures plated at the same cell density were maintained for 1 , $2,3,4$, or 5 weeks in the presence of NGF, rinsed twice with cold PBS, lysed in $250 \mu \mathrm{l}$ of reducing sample buffer containing $50 \mathrm{mM}$ Tris- $\mathrm{HCl}, \mathrm{pH}$ $6.8,100 \mathrm{~mm}$ dithiothreitol, $2 \%$ SDS, $0.1 \%$ bromophenol blue, and $10 \%$ glycerol, and stored at $-70^{\circ} \mathrm{C}$ until use. The amount of protein in each lysate was assessed with the dotMETRIC protein assay according to the manufacturer's instructions (Geno Technology Inc., St. Louis, MO). The samples were boiled for $5 \mathrm{~min}$, and $30 \mu \mathrm{g}$ of protein was loaded on a $12 \%$ SDS-polyacrylamide gel. After separation, protein was transferred to an Immobilon-P nylon membrane (Millipore, Bedford, MA). Blots were blocked for $1 \mathrm{hr}$ at RT with TBST (10 mM Tris-HCl, $\mathrm{pH}$ 7.5, $100 \mathrm{~mm}$ $\mathrm{NaCl}$, and $0.1 \%$ Tween 20 ) plus $5 \%$ nonfat dry milk, washed in TBST, and incubated overnight at $4^{\circ} \mathrm{C}$ in an anti-BAX antibody $(\mathrm{P} 19,100 \mu \mathrm{g} / \mathrm{ml}$ Santa Cruz Biotechnology) diluted 1:1000 in $10 \mathrm{~mm}$ Tris-HCl, $\mathrm{pH} 7.5$, $100 \mathrm{~mm} \mathrm{NaCl}, 0.05 \%$ Tween 20 , and $5 \%$ BSA (w/v). At this concentration of antibody, the signal was linear with respect to the amount of protein (data not shown). After washing, blots were incubated for $1 \mathrm{hr}$ at RT in anti-rabbit alkaline phosphatase-linked antibody (New England Biolabs) diluted 1:1000 in TBST plus 5\% nonfat dry milk. After washing, blots were exposed to CDP-Star (Tropix, Bedford, MA) for $5 \mathrm{~min}$, developed for $1 \mathrm{hr}$, and then exposed to autoradiography film (NEN, Boston, MA). This anti-BAX antibody recognizes a $21 \mathrm{kDa}$ protein in wild-type mouse tissue and does not detect any protein of this size in tissue harvested from Bax-deficient mice (data not shown). The film was scanned and analyzed with ImageQuant (Molecular Dynamics). After analysis of BAX, blots were stripped with $0.2 \mathrm{M}$ glycine, $\mathrm{pH} 2.2,1.0 \%$ Tween 20 , and $0.1 \%$ SDS, washed, blocked, and incubated overnight at $4^{\circ} \mathrm{C}$ in anti-BCLx ${ }_{\mathrm{L}}$ antibody (Transduction Laboratories, Lexington, $\mathrm{KY}$ ) diluted 1:500 in $10 \mathrm{~mm}$ Tris- $\mathrm{HCl}, \mathrm{pH} 7.5,100 \mathrm{~mm} \mathrm{NaCl}, 0.05 \%$
Tween 20, and 5\% BSA (w/v). After washing, blots were incubated for 1 $\mathrm{hr}$ at RT in anti-goat alkaline phosphatase-linked antibody (Tropix) diluted 1:5000 in TBST plus 5\% nonfat dry milk. After washing, blots were exposed to CDP-Star for $5 \mathrm{~min}$, allowed to develop for $1 \mathrm{hr}$, and then exposed to autoradiography film (NEN).

\section{RESULTS}

\section{Mature sympathetic neurons do not lose viability when deprived of NGF}

We first examined the phenomenon of trophic factor independence in long-term cultures of sympathetic neurons. Neurons isolated from the superior cervical ganglia of embryonic rats were maintained $23 \mathrm{~d}$ in vitro (DIV) in the presence of NGF. After $16 \mathrm{~d}$ of NGF deprivation, we counted the number of viable neurons remaining in these mature neuronal cultures and compared this with the number of neurons surviving in young cultures after $2 \mathrm{~d}$ of NGF deprivation (Fig. $1 E$ ). In contrast to the profound cell loss that occurs in the young neurons (6 DIV) after trophic factor withdrawal, cell number was not reduced in the NGF-deprived mature cultures. Viability of the NGF-deprived mature neurons was assessed by several criteria, including phase-contrast microscopy (Fig. $1 H, I)$, crystal violet staining (Fig. 1A,B) (Deckwerth and Johnson, 1993), and calcein AM fluorescence (Fig. 1J,K) (Bozycko et al., 1993). By all these criteria, mature neurons remained viable after NGF removal. Unlike young neurons, which undergo chromatin condensation and DNA fragmentation after NGF withdrawal (Deckwerth and Johnson, 1993), these mature neurons did not experience any apparent changes in their nuclear morphology, as observed by staining with the dye Hoechst 33258 (Fig. $1 F, G$ ).

\section{Mature neurons atrophy in the absence of NGF}

Although mature sympathetic neurons do not undergo cell death in response to trophic factor deprivation, the removal of NGF significantly reduces the cell volume (Koike and Tanaka, 1991). In mature sympathetic cultures (23 DIV), this atrophy was very striking after $16 \mathrm{~d}$ of NGF deprivation (Fig. 1). The cell diameter of mature neurons was reduced to $14 \mu \mathrm{m}$ after $16 \mathrm{~d}$ of NGF deprivation, whereas neurons maintained in NGF during this time had an average cell diameter of $27 \mu \mathrm{m}$ (Fig. $2 A$ ). The reduction in cell size was also reflected by a decrease in protein content of the neuronal cultures (Fig. 2B). After $7 \mathrm{~d}$ of NGF deprivation, total neuronal protein was decreased to $66 \%$ of the NGF-maintained, control cultures.

\section{Mature sympathetic neurons undergo the early metabolic changes after NGF removal}

This atrophy and reduction in protein content of mature neurons in response to NGF deprivation is reminiscent of the changes observed in young neurons before they die by apoptosis (Deckwerth and Johnson, 1993). To examine whether similarities exist between young and mature neurons early after NGF deprivation, we examined whether NGF withdrawal in mature neurons initiates the rapid decline in metabolic parameters, such as protein synthesis, RNA synthesis, and glucose uptake (Deckwerth and Johnson, 1993).

When mature neurons were deprived of NGF, the rate of protein synthesis decreased to $57 \%$ of the level in NGFmaintained cultures within 12 hr (Fig. 3, $\mathbf{\Delta}$ ) followed by a slow decline to $30 \%$ by $12 \mathrm{~d}$. Similarly, the rate of RNA synthesis fell to $51 \%$ of control levels within the first $6 \mathrm{hr}$ after NGF depriva- 

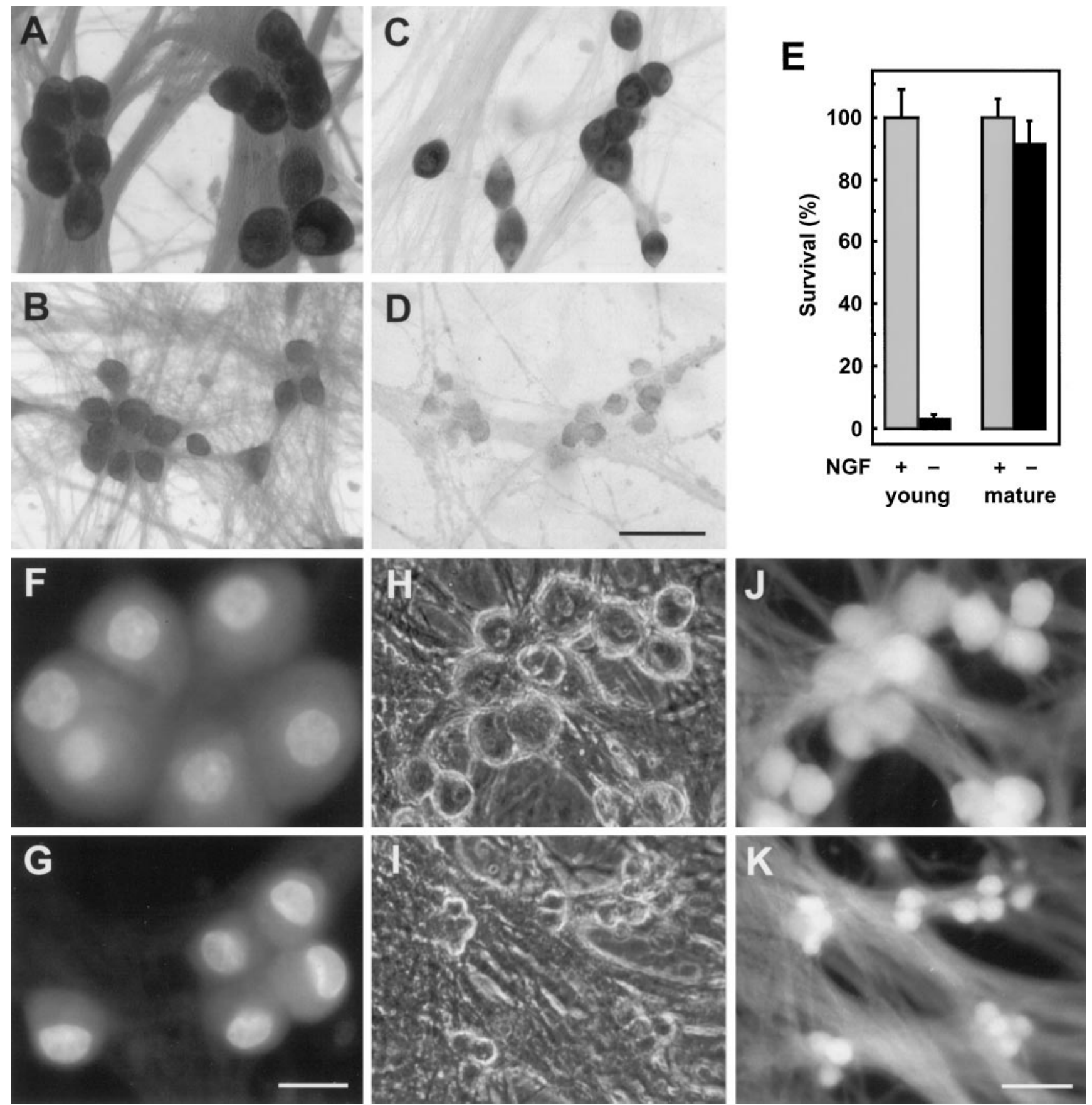

Figure 1. Mature sympathetic neurons are resistant to NGF deprivation. Neurons that had been maintained for $23 \mathrm{~d}$ in vitro (DIV) were either continued in $\operatorname{AM} 50(A)$ or deprived of $\operatorname{NGF}(B)$ for $16 \mathrm{~d}$, and then fixed and stained with crystal violet, as described in Materials and Methods. In parallel, six DIV neurons were either maintained in AM50 $(C)$ or deprived of NGF $(D)$ for $2 \mathrm{~d}$ before staining with crystal violet. Viable cells were counted as described in Materials and Methods. The number of neurons remaining in the NGF-deprived cultures is expressed as a percentage of the number of viable neurons in the NGF-maintained controls $(E)$. Data from four neuronal cultures are shown as mean \pm SD. Mature neurons, 23 DIV, were either maintained in NGF $(F, H, J)$ or deprived of NGF for $16 \mathrm{~d}(G, I, K)$ and then stained with Hoechst $33258(F, G)$ or calcein AM $(J, K)$. Phase-contrast microscopy is shown in $H$ and $I$. Scale bars: $A-D, 50 \mu \mathrm{m} ; F$ and $G, 20 \mu \mathrm{m} ; H-K, 50 \mu \mathrm{m})$.

tion (Fig. 3, $\mathbf{0}$ ). Glucose uptake also decreased in mature neurons, reaching $48 \%$ of control levels $24 \mathrm{hr}$ after NGF deprivation (Fig. 3, ○). This rapid fall in metabolic parameters is similar to that seen in the young SCG neurons deprived of NGF (Deckwerth and Johnson, 1993), although to a somewhat less extent [between 50 and $60 \%$ in mature neurons compared with $\sim 80 \%$ in young neurons (Deckwerth and Johnson, 1993)].

\section{c-Jun becomes phosphorylated in mature SCG neurons after NGF withdrawal}

The transcription factor c-Jun is important for cell death in young sympathetic neurons; its steady-state mRNA level increases within $5 \mathrm{hr}$ after NGF deprivation. The introduction of neutralizing anti-c-Jun antibodies or a dominant negative c-jun expression vector into young neurons blocks trophic factor deprivation- 
A

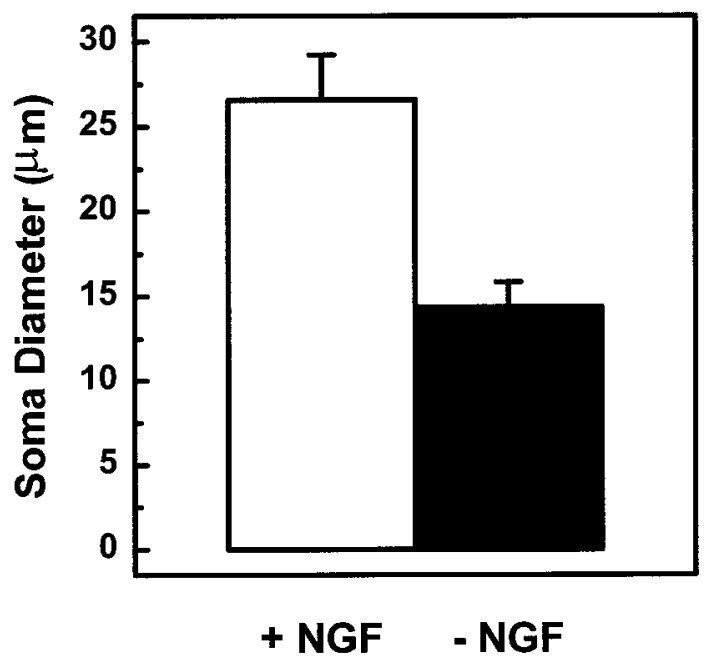

B

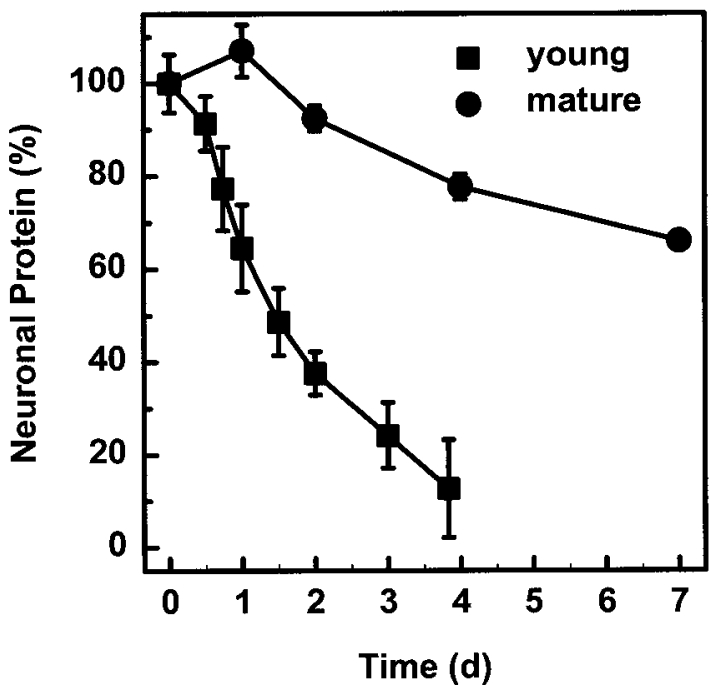

Figure 2. Mature sympathetic neurons undergo early degenerative changes when deprived of NGF. $A$, Soma diameter was measured in 23 DIV neurons that were either maintained in NGF (open bar) or deprived of NGF ( filled bar) for $16 \mathrm{~d}$. The diameters of 30 neurons were measured for each condition. $B$, Total neuronal protein was measured in young and mature neurons after 1, 2, 4, or $7 \mathrm{~d}$ after NGF deprivation. The total neuronal protein of deprived neurons is expressed as a percentage of NGF-maintained cultures. All data are shown as mean \pm SD.

induced cell death (Estus et al., 1994; Ham et al., 1995). The transcriptional activity of c-Jun is greatly enhanced by phosphorylation at serine residues 63 and 73 in the transactivation domain (for review, see Karin, 1995; Karin and Hunter, 1995). In young sympathetic neurons, NGF deprivation induces the appearance of Ser63-phosphorylated c-Jun in the nucleus after $8 \mathrm{hr}$ of NGF deprivation (Deckwerth, Easton, Knudson, Korsmeyer, and Johnson, unpublished data). To examine whether c-Jun becomes phosphorylated on Ser63 in mature sympathetic neurons after NGF withdrawal, mature neuronal cultures were deprived of NGF and immunostained with an antibody specific for phosphoc-Jun. Approximately 6 hr after NGF deprivation, phospho-c-Jun

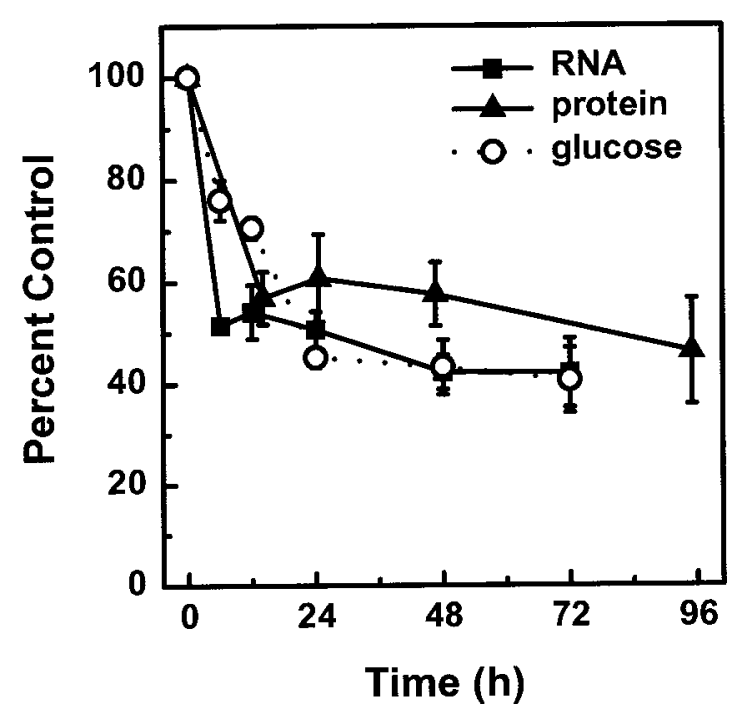

Figure 3. Mature sympathetic neurons undergo the early metabolic changes when deprived of NGF. Neurons maintained in vitro for 3-4 weeks were deprived of NGF for the indicated amounts of time. Protein synthesis $(\boldsymbol{\Delta})$, RNA synthesis $(\boldsymbol{\square})$, and glucose uptake $(\bigcirc)$ were determined as described in Materials and Methods. Each plot depicts the mean and range of two experiments. Within each experiment, two to five neuronal cultures were analyzed per time point.

immunostaining was evident in some neurons, and by $12 \mathrm{hr}$ all of the neurons in the culture were positive. This staining pattern remained at $48 \mathrm{hr}$ (Fig. 4). The immunohistochemistry results were confirmed by Western blot analysis of mature neurons that had been deprived of NGF for $24 \mathrm{hr}$ (data not shown). Thus, NGF deprivation triggered c-Jun phosphorylation in mature neurons.

\section{Mature neurons undergo the early but not the late phase of gene induction after NGF deprivation}

Because phosphorylated c-Jun is capable of activating its own transcription (Angel et al., 1988), we next examined whether c-jun mRNA was increased in mature neurons after trophic factor deprivation. An early wave of gene induction, which occurs within $5 \mathrm{hr}$ after NGF deprivation of young neurons, includes c-jun. Induction of c-jun and other genes, such as c-myb, $m k p-1$, and cyclin D1, occurs before a second, late wave of gene expression, which occurs $15 \mathrm{hr}$ after NGF deprivation and includes c-fos, fos $B, N G F I-A$, and $r h l$ expression (Estus et al., 1994; Freeman et al., 1994).

To determine whether the two phases of gene induction occur in mature neurons, we isolated mRNA from neurons at various times after NGF deprivation and evaluated the amount of specific mRNAs by using semiquantitative RT-PCR. mRNA levels of c-jun, representative of the early genes, increased dramatically in mature neurons (Fig. 5B). Similar to young neurons, the initial increase was observed by $6 \mathrm{hr}$ after NGF deprivation. In mature neurons, however, the c-jun mRNA level continued to increase, peaked at $48 \mathrm{hr}$, and remained elevated at $96 \mathrm{hr}$ after NGF deprivation, whereas in young neurons levels declined to baseline as the cells died. The expression of c-jun mRNA corresponded well with the time course of phospho-c-Jun staining in older SCG neurons. Another early gene $(m k p-1)$ also increased in mature neurons within $6 \mathrm{hr}$ after NGF deprivation, showed a maximum induction after $36 \mathrm{hr}$, and remained elevated (Fig. 5B). In contrast, examination of c-fos, representative of the late phase of 

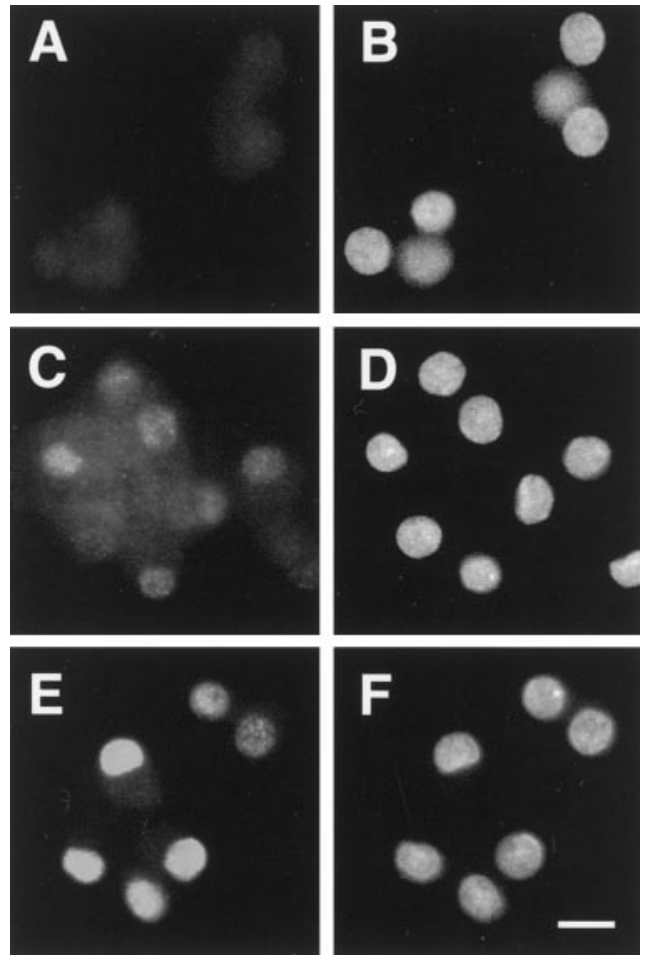

Figure 4. The phosphorylated form of c-Jun increases after trophic factor deprivation. After 4 weeks in vitro, SCG neurons were deprived of NGF for a given amount of time, fixed in $4 \%$ paraformaldehyde, and stained with an antibody against the phosphorylated form of c-Jun. Phospho-c-Jun immunoreactivity $(A, C, E)$ and Hoechst 33258 staining $(B, D, F)$ are shown. c-Jun became phosphorylated by $6 \mathrm{hr}$ after deprivation and was localized to the nucleus $(C, D)$. An increase in phosphoc-Jun did not occur with medium change alone $(A, B)$. Twelve hours after NGF deprivation all neurons in the culture were brightly stained (data not shown) and remained positive out to $48 \mathrm{hr}(E, F)$. Similar results were observed in two separate experiments. Scale bar, $20 \mu \mathrm{m}$.

gene induction in young neurons, failed to demonstrate any increase in the mRNA level in NGF-deprived, mature neurons (Fig. $5 C)$. Similarly, fos $B$, another gene induced during this late phase in young neurons, was not induced (Fig. $5 C$ ). In the matching young cultures, however, both genes showed substantial induction with a time course similar to that described previously (Estus et al., 1994).

In response to NGF deprivation, mature neurons, like young neurons, experienced a rapid decrease in metabolism and induction of c-jun and $m k p-1$, which are members of the first phase of gene induction, after NGF withdrawal. In contrast to young neurons, however, mature neurons experienced a block in the pathway before the induction of the second group of genes.

\section{Bax overexpression in mature sympathetic neurons restores acute trophic factor dependence for survival}

The position of the block between the first and second phases of gene induction in mature neurons was indistinguishable from that observed in young sympathetic neurons deficient in Bax (Deckwerth, Easton, Knudson, Korsmeyer, and Johnson, unpublished data). This block preceded activation of the caspases, the inhibition of which arrests the apoptotic program downstream of the second phase of gene induction (Deshmukh et al., 1996). This similarity with the properties of Bax-deficient young neurons was surprising, in that mature sympathetic neurons express Bax mRNA at levels comparable to young neurons (Greenlund et al.,
1995), which we confirmed in an independent set of experiments (data not shown). To examine whether BAX protein is expressed in mature neurons, the level of BAX protein was examined in 1to 5-week-old cultures by Western blot analysis with anti-BAX antibodies. No difference in BAX protein levels could be detected (Fig. 6). Likewise, BAX protein levels in superior cervical ganglia removed from 4-week-old rats were comparable to the levels of embryonic day 21 SCG (data not shown). This discrepancy led us to hypothesize that endogenous BAX may not be able to function adequately in mature neurons and that this insufficient BAX function might underlie the decline in sensitivity to trophic factor withdrawal during maturation. To test this hypothesis, we microinjected a Bax-expressing plasmid into mature sympathetic neurons and examined whether the overexpression of Bax could restore acute trophic factor dependence to mature sympathetic neurons.

Bax overexpression in mature neurons did not significantly diminish the viability of neurons that were maintained in NGF; however, when NGF was withdrawn, the Bax-overexpressing neurons underwent cell death (Fig. 7). In Bax-overexpressing neurons, survival was reduced to $40 \%$ after $48 \mathrm{hr}$ of NGF deprivation. Neurons that had been injected with the control vector did not die in either the presence or absence of NGF. Therefore, overexpression of exogenous BAX restores trophic factor dependence to mature sympathetic neurons.

\section{Bax overexpression restores the apoptotic program in mature sympathetic neurons deprived of NGF}

To test whether Bax overexpression fully restored the apoptotic program activated by NGF deprivation, we determined whether late events, such as c-Fos expression, caspase activation, and nuclear condensation, that are characteristic of apoptosis in young neurons indeed occurred. The nuclear chromatin of Baxoverexpressing mature cells condensed and marginated after NGF withdrawal, in contrast to the healthy appearance of the nuclei of NGF-maintained, Bax-injected cells (compare Figs. 7, 8). In addition, mature neurons injected with the Bax-expressing vector were examined by immunohistochemistry for nuclear c-Fos accumulation. As seen in young cultures (Estus et al., 1994; Ham et al., 1995), a minor fraction of apoptotic nuclei showed increased nuclear staining for c-Fos, consistent with the activation of the second phase of gene expression in at least these c-Fospositive neurons (Fig. 8). As observed in young neurons after NGF withdrawal, cells displaying c-Fos immunoreactivity also exhibited marginated or condensed chromatin. Most important, treatment of Bax-injected mature neurons with the caspase inhibitor BAF prevented death of these neurons after NGF deprivation (Fig. 9), demonstrating that the apoptotic program in mature neurons expressing exogenous Bax passed through the caspase checkpoint located downstream of the BAX checkpoint (Deshmukh et al., 1996) (Deckwerth, Easton, Knudson, Korsmeyer, and Johnson, unpublished data). Taken together, these data suggest that the terminal pathway activated by NGF deprivation in mature neurons with restored BAX function is similar to that taken by young neurons deprived of NGF.

\section{Levels of BCL2 and BCLx $x_{L}$ are similar in young and mature neurons}

The ratio of BAX to other members of the BCL2 family is an important determinant of the susceptibility of the cell to deathinducing stimuli (Oltvai and Korsmeyer, 1994). Although an absence of BAX protein cannot explain the deficiency in BAX 
A. cyclophilin
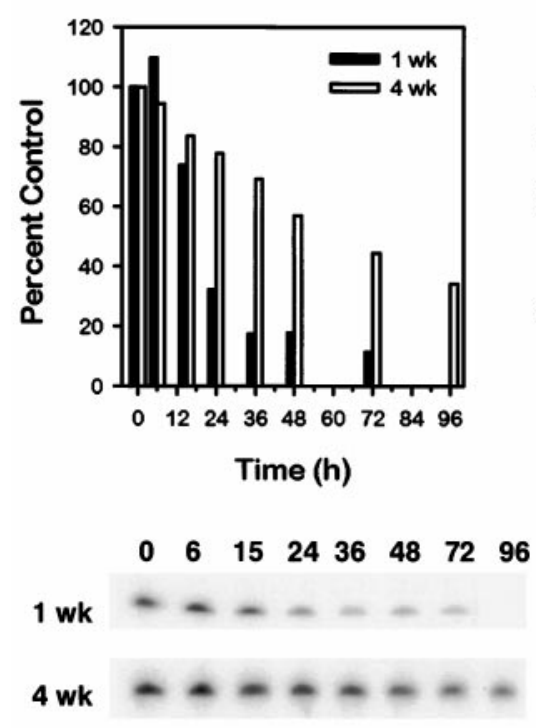

B. c-jun

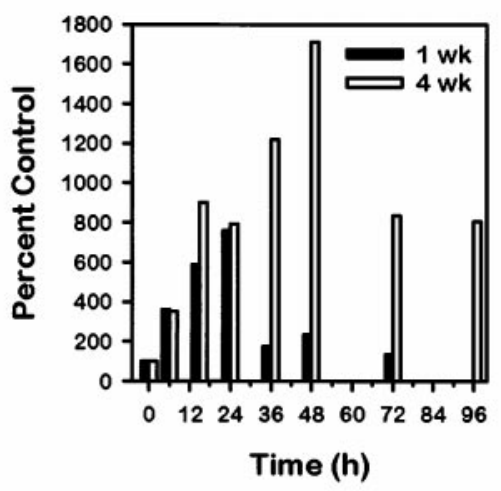

$\begin{array}{llllllll}0 & 6 & 15 & 24 & 36 & 48 & 72 & 96\end{array}$

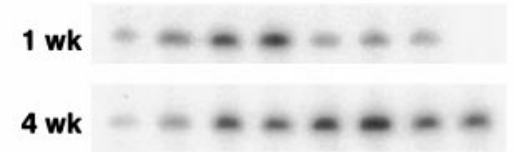

$m k p-1$

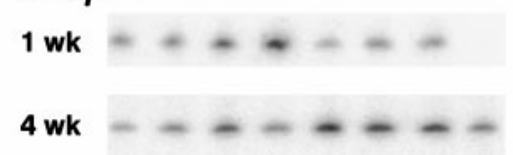

C. $c$-fos

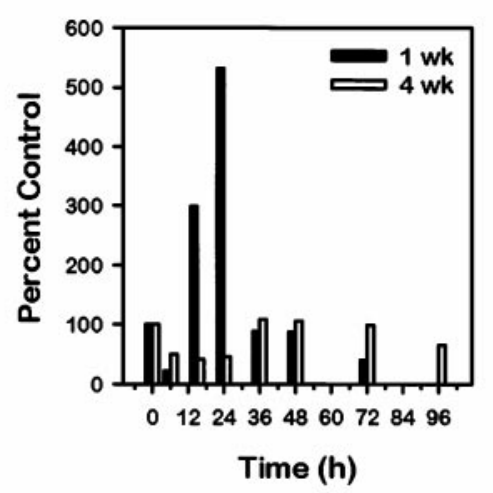

$\begin{array}{llllllll}0 & 6 & 15 & 24 & 36 & 48 & 72 & 96\end{array}$

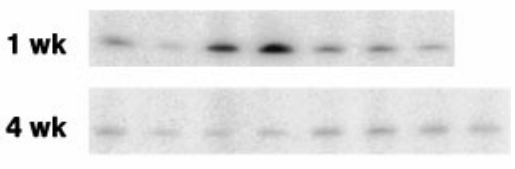

fos $B$

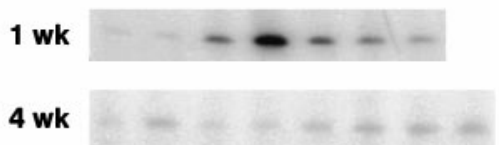

Figure 5. Mature sympathetic neurons experience a block between the first and second phases of gene induction after NGF deprivation. After one ( filled bar) or four (open bar) weeks in vitro, neuronal cultures were deprived of NGF, and cDNA was prepared at specific times after deprivation. PCR analysis was conducted, as described in Materials and Methods, and the representative genes are depicted. A, cyclophilin has been demonstrated previously to decrease in young SCG neurons deprived of NGF. $B$, c-jun and $m k p-1$ are genes induced during the first phase of gene induction (by 6 hr) after NGF deprivation. Quantitation for c-jun is shown in the graph. $C$, c-fos and fos $B$ are among the late genes that increase by $10-15$ hr after NGF deprivation. This same increase was seen in our young neurons (1 week in vitro) deprived of NGF but not in the matched mature cultures (4 weeks in vitro). Quantitation for c-fos is shown in the graph. The data shown are from one preparation of neuronal cultures. Data are expressed as percentages of the NGF-maintained culture. These results have been confirmed in an independent time course.

function in mature sympathetic neurons, a functional decrease in BAX could be caused by increased levels of anti-apoptotic members of the BCL2 family, such as BCL2 and BCLx $x_{L}$, yet the existing evidence does not support this hypothesis. Bcl2 mRNA and BCL2 protein levels do not change on maturation (Greenlund et al., 1995). Furthermore, neurons isolated from Bcl2-deficient mice develop resistance to acute trophic factor deprivation, excluding a role for BCL2 in this phenomenon (Greenlund et al., 1995). Given that neuronal death in $B c l x_{\mathrm{L}}$-deficient mice is greatly enhanced (Motoyama et al., 1995), and that overexpression of $\mathrm{BCLx}_{\mathrm{L}}$ blocks trophic factor deprivation-induced cell death (Gonzalez-Garcia et al., 1995), BCLx $\mathrm{L}_{\mathrm{L}}$ may be a more important regulator of neuronal cell death than BCL2. Thus, we examined the level of $\mathrm{BCLx}_{\mathrm{L}}$ protein in young and mature sympathetic cultures by Western blot analysis. We found no difference in the level of protein in neurons over 5 weeks in culture (Fig. 6). In addition, BCLx $\mathrm{L}_{\mathrm{L}}$ protein levels were similar in superior cervical ganglia isolated from embryonic and 4-week-old rats (data not shown). Although $B c l x_{\mathrm{L}}$ mRNA did not change over time in vitro, it is possible that mature neurons upregulate $B c l x_{\mathrm{L}}$ mRNA in response to NGF deprivation. We examined $B c l x_{\mathrm{L}}$ mRNA levels after NGF deprivation of neurons maintained in vitro for either 1 or 4 weeks and found no induction of $B c l x_{\mathbf{L}}$ mRNA (data not shown). As observed previously in young SCG neurons (Greenlund et al., 1995), Bclx $x_{\mathrm{L}}$ mRNA decreased after NGF deprivation of mature neurons. In addition, by Western blot analysis, BCLx $\mathrm{L}_{\mathrm{L}}$ protein levels did not change after NGF deprivation of mature neurons, which was similar to what was observed in young neurons (data not shown). Thus, a change in the expression of BCL2 or $\mathrm{BCLx}_{\mathrm{L}}$ does not account for the resistance of mature neurons to trophic factor deprivation.

\section{DISCUSSION}

\section{Potential mechanisms for an increased resistance of mature neurons to trophic factor deprivation}

Several mechanisms may explain the increased resistance of mature sympathetic neurons to NGF deprivation. For instance, mature neurons may survive for an extended period in the absence of NGF because they obtain another source of trophic support, either from the autocrine production of a neurotrophic factor or the constitutive augmentation of trophic factor signaling pathways. An alternative source of trophic support would be expected to maintain MAP kinase activation and the basal metabolism of the neuron. NGF deprivation of mature neurons, however, produced rapid decreases in MAP kinase phosphorylation (data not shown) and in the rates of neuronal protein and RNA synthesis (Fig. 3). Consistent with these data, mature neurons undergo a substantial decrease in cell size after NGF deprivation both in vitro (Fig. 2A) (Koike and Tanaka, 1991) and in vivo (Levi-Montalcini and Angeletti, 1966; Bjerre et al., 1975; Goedert et al., 1978; Otten et al., 1979; Gorin and Johnson, 1980; Ruit et al., 1990). The maintenance of normal neuronal morphol- 


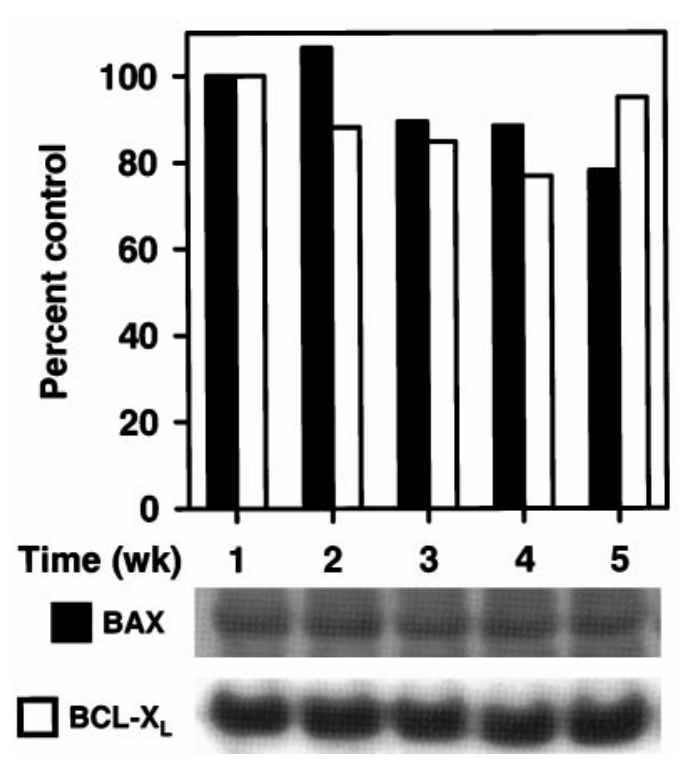

Figure 6. $\mathrm{BAX}$ and $\mathrm{BCLx}_{\mathrm{L}}$ protein levels do not change over time in vitro. After 1-5 weeks in culture, neurons were lysed in reducing sample buffer and stored at $-70^{\circ} \mathrm{C}$. After completion of the time course, the amount of protein was quantified by dotMETRIC analysis, and an equal amount of protein was loaded in each lane. After SDS-PAGE and transfer, the blot was probed with a rabbit polyclonal antibody against BAX, as described in Materials and Methods. The same blot was stripped and probed again with an antibody against $\mathrm{BCLx}_{\mathrm{L}}$. After each primary antibody, the blot was probed with a secondary antibody conjugated to alkaline phosphatase, developed with CDP-Star, and exposed to autoradiography film. The film was scanned and quantified by using ImageQuant. Data shown in the graph are expressed as a percentage of the amount of protein after 1 week in culture. Similar results were observed in four independent experiments.

ogy and metabolic activity appears to require NGF. Thus, our results along with previous in vivo data argue against the possibility of an alternative trophic factor or constitutive activation of a survival signal at the level of the trophic factor receptor.

Alternatively, neuronal death after acute trophic factor withdrawal can be prevented by a block in the events between trophic factor removal and the ultimate death that occurs in young cells. The data presented in this paper support the presence of a block in the apoptotic pathway and define approximately at which point in the sequence of events this block occurs.

\section{Defining the step at which programmed cell death is aborted in mature neurons: a comparison to Bax- deficient and to caspase-inhibited neurons}

Similar to the ability of maturation to protect neurons from acute cell death after trophic factor removal, the deletion of Bax in young sympathetic neurons (Deckwerth et al., 1996) or the treatment of young neurons with the caspase inhibitor BAF (Deshmukh et al., 1996) also protects cells from NGF deprivation. In addition, neurons protected from cell death by any one of these mechanisms undergo significant atrophy in the absence of NGF. A comparison of the events that occur in mature neurons after NGF withdrawal with the other two paradigms defines the step at which programmed cell death is aborted in mature neurons. Similar to mature neurons, NGF deprivation produces a decrease in metabolic parameters and an increase in c-jun mRNA levels in both Bax-deficient neurons (Deckwerth, Easton, Knudson, Korsmeyer, and Johnson, unpublished data) and BAF-treated cells
$\mathbf{A}$

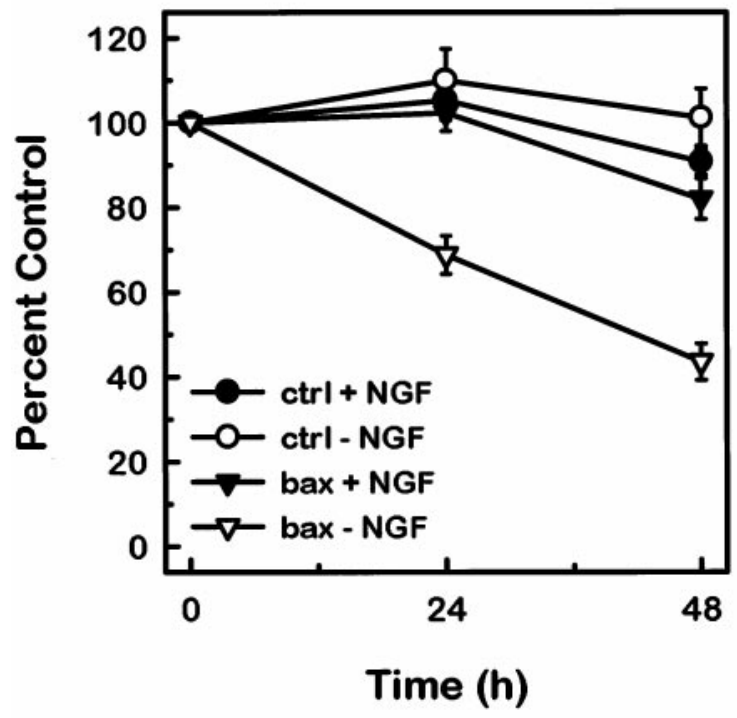

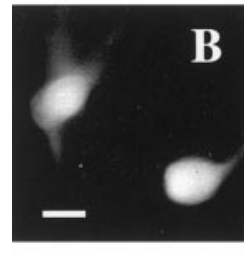

GFP

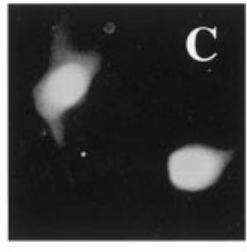

Anti-FLAG

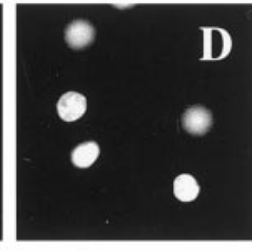

Hoechst
Figure 7. Bax expression in mature sympathetic neurons restores NGF dependence. $A$, Primary SCG neurons that had been maintained in vitro for $26 \mathrm{~d}$ were co-injected with pGreenLantern-1 and either pcDNA3 vector $(\bigcirc, \bigcirc ; n=1271)$ or FLAG-Bax $(\boldsymbol{\nabla}, \nabla ; n=750)$. Sixteen to $24 \mathrm{hr}$ after injection, microinjected cells were counted on the fluorescent microscope, and this number was used as the baseline. Scored neurons were GFP-positive (fluorescent green) and phase-bright. Half of the injected cultures was maintained in $\operatorname{NGF}(\boldsymbol{\nabla}, \boldsymbol{\nabla})$, whereas the other half was switched to medium containing a neutralizing antibody against NGF $(\bigcirc, \nabla)$. At 24 and $48 \mathrm{hr}$ after treatment, the GFP-positive, phase-bright neurons were counted by a naive observer. The numbers of neurons scored at 24 and $48 \mathrm{hr}$ are expressed as a percentage of the baseline count. The mean and SE for six experiments are shown. In each experiment, 39-196 neurons were injected for each condition. Comparison between $B a x$-injected and control-injected neurons revealed that in the absence of NGF, the two conditions are significantly different at 24 and $48 \mathrm{hr}(p<$ 0.05). Bax-injected and control-injected neurons in the presence of NGF have no statistically significant difference at 24 and $48 \mathrm{hr}$. Data passed tests for normality and equivalency, so statistical significance was assessed by using a one-way ANOVA and Tukey test. To confirm the production of the transgene, neurons were microinjected with FLAG-Bax, maintained in NGF for 16-24 hr $(B-D)$, and then fixed and stained with an antiFLAG antibody $(C)$. GFP $(B)$ marks the microinjected neurons, and Hoechst 33258 staining $(D)$ reveals healthy nuclei. Scale bar, $20 \mu \mathrm{m}$.

(Deshmukh et al., 1996). Unlike mature neurons, however, BAFsaved neurons progress through the pathway to induce c-fos in response to trophic factor withdrawal (Deshmukh et al., 1996). Bax-deficient neurons, on the other hand, do not undergo c-fos induction (Deckwerth, Easton, Knudson, Korsmeyer, and Johnson, unpublished data). The failure of Bax-deficient neurons to undergo the second wave of gene expression is the same as is seen in the mature neurons (Fig. 5). In addition, the profile of c-jun 

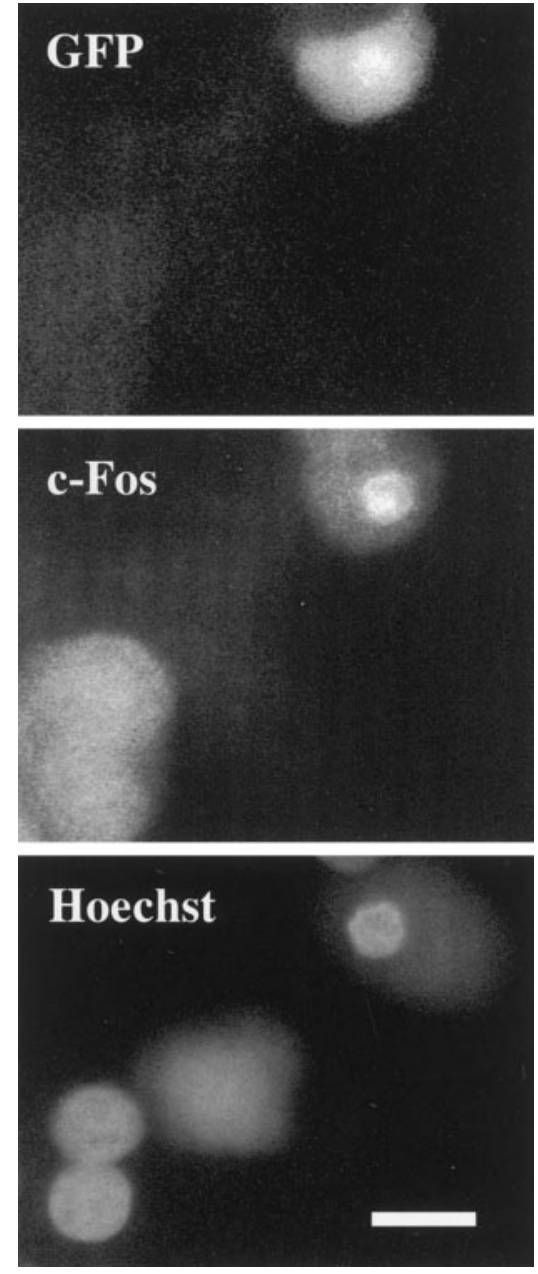

Figure 8. BAX restores the apoptotic program in mature sympathetic neurons deprived of NGF. Twelve hours after NGF deprivation, injected neurons were fixed and stained with an antibody against c-Fos. Neurons injected with Bax were marked by GFP fluorescence and showed nuclear c-Fos immunoreactivity. Nuclear staining with Hoechst 33258 demonstrated that nuclei that were c-Fos-positive displayed abnormal morphology. The nucleus of the injected cell was condensed and smaller than its uninjected neighbor. c-Fos immunoreactivity was not seen in pcDNA3 (vector alone)-injected neurons after NGF deprivation.

expression is similar in Bax-deficient neurons and mature cells. From this analysis, the mature neurons were blocked after trophic factor withdrawal at a point at or near the BAX checkpoint.

\section{Potential mechanisms for the block in the apoptotic pathway in mature neurons}

From our analysis, the mature neurons were blocked in the apoptotic pathway at a point indistinguishable from $B a x$-deficient young neurons and, as shown in Figure 7, the overexpression of BAX restored acute dependence of the mature neuron on NGF for survival. These data suggest that a loss in BAX expression may account for the resistance of the mature sympathetic neuron to trophic factor deprivation. However, Bax mRNA levels in young and mature neurons are not different (Greenlund et al., 1995), and we did not detect any decrease in BAX protein levels in mature sympathetic neurons in vitro or in vivo (Fig. 6). Thus, a decrease in BAX does not account for the maturation-induced block in sympathetic neurons. Alternatively, if the pathway down-

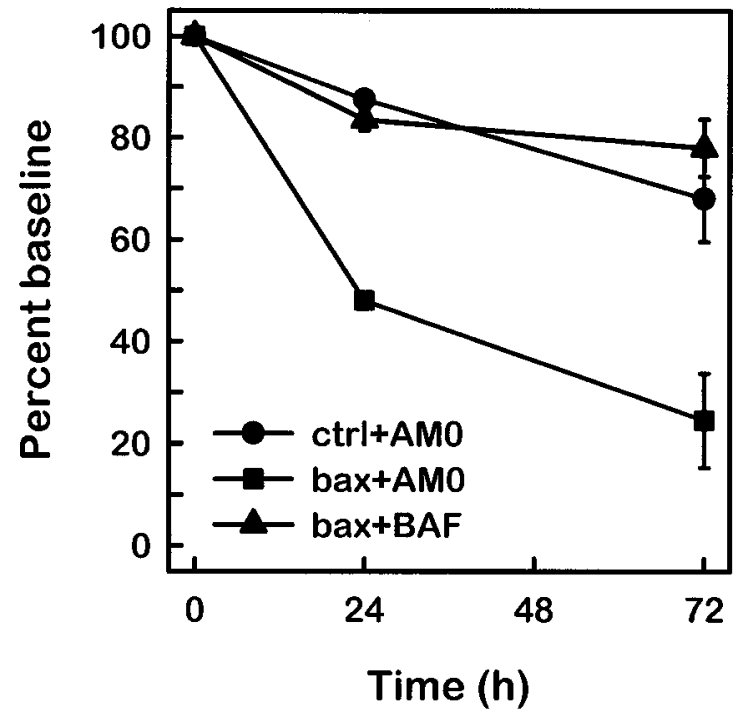

Figure 9. Cell death induced by NGF deprivation of BAX-expressing mature neurons is inhibited by the caspase inhibitor BAF. Twenty-six DIV SCG neurons were co-injected with GFP and either pcDNA3 vector (O) or FLAG-Bax (ם, $\mathbf{\Delta})$. Sixteen to $24 \mathrm{hr}$ after injection, microinjected cells were counted on the fluorescent microscope, and this number was used as the baseline. Scored neurons were GFP-positive (fluorescent green) and phase-bright. After this baseline count, the neurons were switched to medium containing neutralizing antibodies to NGF with $(\boldsymbol{\Delta})$ or without $30 \mu \mathrm{M} \operatorname{BAF}(\mathbf{O}, \mathbf{\square})$. At 24 and $48 \mathrm{hr}$ after treatment, the GFP-positive, phase-bright neurons were counted by a naive observer. The numbers of neurons scored at 24 and $48 \mathrm{hr}$ after treatment are expressed as a percentage of the baseline count. The mean and range of two experiments are depicted.

stream of BAX were completely disabled in the mature neuron, the maturation-induced block would be indistinguishable from the BAX checkpoint. This is clearly not the case, because overexpression of BAX restores trophic factor dependence in the mature neuron, and the mature neurons resume the apoptotic pathway characteristic of NGF-deprived young neurons. Thus, the effector pathway is at least qualitatively functional, although it may be less active and may require higher amounts of BAX for activation. A less active effector pathway in mature neurons may explain why BAX overexpression in mature neurons did not induce cell death in the presence of NGF as it does in young neurons (Vekrellis et al., 1997).

Alternatively, survival of mature neurons in the absence of NGF may be attributable to inactivation of BAX by dimerization with anti-apoptotic members or a survival-promoting activity of another BCL2 family member acting independent of BAX. This is less likely to be true for the anti-apoptotic members BCL2 or $\mathrm{BCLx}_{\mathrm{L}}$, because their expression is not altered in mature neurons (Greenlund et al., 1995) (Fig. 6); however, other antiapoptotic family members may be responsible. Alternatively, other proapoptotic family members that neutralize BCL2 or BCLx $\mathrm{L}_{\mathrm{L}}$ may be diminished and thereby may make BCL2 and $\mathrm{BCLx}_{\mathrm{L}}$ more active in mature neurons. BCL2 alone is clearly not responsible, because $B c l 2$-deficient mature neurons do not die after NGF withdrawal (Greenlund et al., 1995). However, Bcl2-deficient neurons are weakened in vivo and die progressively in the adult animal (Michaelidis et al., 1996), indicating some effect of BCL2 on neuronal viability.

Besides modulation of other BCL2 family members, an alternate way to modulate BAX function may be through a post- 
translational modification associated with maturation. For example, phosphorylation modulates the function of other BCL2 family members, including BCL2 and BAD (Haldar et al., 1995; Zha et al., 1996; Ito et al., 1997). BAX function may also be altered by different compartmentalization of BAX itself or of other proapoptotic and antiapoptotic family members in mature neurons compared with young neurons (Hsu et al.,1997).

These changes discussed above would produce a phenotype similar to the Bax-deficient young neurons. A modification that blocks the function of BAX would obviate the need for NGF to maintain survival. However, NGF would still be essential for maintaining neuronal cell size and function.

\section{Implications of neuronal resistance to trophic factor withdrawal}

These results demonstrate that loss of the acute dependence of the neuron on trophic factor for survival is not caused by a complete loss of trophic factor requirement for neuronal function. Instead, the resistance of the mature neuron to acute cell death after trophic factor withdrawal is caused by the abortion of the pathway associated with programmed cell death at a point just before the caspase activation and indistinguishable from the BAX checkpoint. The development of this resistance occurs in a number of neuronal populations and may serve a protective function in the nervous system. The central importance of BAX to cell death in a number of neuronal populations (Deckwerth et al., 1996; Miller et al., 1997) suggests that a common mechanism for the resistance of mature neurons to acute trophic factor deprivation may be accomplished by the modulation of BAX function. This may be achieved in some neuronal populations by a decrease in BAX protein expression, as occurs in the cortex and cerebellum (Vekrellis et al., 1997). In other neuronal populations, such as the sympathetic nervous system, BAX function may be decreased by a post-translational modification or alterations in other BCL2 family members.

An inability of the mature neuron to develop or maintain this resistance to apoptosis may contribute to the development of neurodegenerative diseases. A reversal in the maturation process would cause the adult neuronal population to become acutely dependent on trophic factors for survival. This acute dependence on trophic factors may lead to neuronal cell death in the face of a limiting availability of neurotrophic factors. Thus, neuronal cell loss in neurodegenerative disease may involve not only decreased neurotrophic factor supply but also an increased dependence on trophic factors for neuronal survival.

\section{REFERENCES}

Angel P, Hattori K, Smeal T, Karin M (1988) The jun proto-oncogene is positively autoregulated by its own product, Jun/AP-1. Cell 55:875-885.

Angeletti PU, Levi-Montalcini R, Caramia F (1971) Analysis of the effects of the antiserum to the nerve growth factor in adult mice. Brain Res 27:343-355.

Bjerre B, Wiklund L, Edwards DC (1975) A study of the de- and regenerative changes in the sympathetic nervous system of the adult mouse after treatment with the antiserum to NGF. Brain Res 92:257-278.

Bozycko CD, McKenna BW, Connors TJ, Neff NT (1993) A rapid fluorometric assay to measure neuronal survival in vitro. J Neurosci Methods 50:205-216.

Chalfie M, Tu Y, Euskirchen G, Ward WW, Prasher DC (1994) Green fluorescent protein as a marker for gene expression. Science 263:802-805.

Chun LLY, Patterson PH (1977) Role of nerve growth factor in the development of rat sympathetic neurons in vitro II. developmental studies. J Cell Biol 75:705-711.

Deckwerth TL, Johnson Jr EM (1993) Temporal analysis of events associated with programmed cell death (apoptosis) of sympathetic neurons deprived of nerve growth factor. J Cell Biol 123:1207-1222.

Deckwerth TL, Elliot JL, Knudson CM, Johnson Jr EM, Snider WD, Korsmeyer SJ (1996) BAX is required for neuronal death after trophic factor deprivation and during development. Neuron 17:401-411.

Deshmukh M, Vasilakos J, Deckwerth TL, Lampe PA, Shivers BD, Johnson Jr EM (1996) Genetic and metabolic status of NGF-deprived sympathetic neurons saved by an inhibitor of ICE family proteases. J Cell Biol 135:1341-1354.

Estus S (1997) Optimization and validation of RT-PCR as a tool to analyze apoptotic gene expression. In: Neuromethods: apoptosis techniques and protocols (Poirier J, ed), pp 67-84. Totowa, NJ: Humana.

Estus S, Zaks WJ, Freeman RS, Gruda M, Bravo R, Johnson Jr EM (1994) Altered gene expression in neurons during programmed cell death: identification of c-jun as necessary for neuronal apoptosis. J Cell Biol 127:1717-1727.

Farrow SN, White JHM, Martinou I, Raven T, Pun K-T, Grinham CJ, Martinou J-C, Brown R (1995) Cloning of a bcl-2 homologue by interaction with adenovirus E1B19K. Nature 374:731-733.

Freeman RS, Estus S, Johnson Jr EM (1994) Analysis of cell cyclerelated gene expression in postmitotic neurons: selective induction of cyclin D1 during programmed cell death. Neuron 12:343-355.

Garcia I, Martinou I, Tsujimoto Y, Martinou J-C (1992) Prevention of programmed cell death of sympathetic neurons by the $b c l-2$ protooncogene. Science 258:302-304.

Goedert M, Otten U, Thoenen H (1978) Biochemical effects of antibodies against NGF on developing and differentiated ganglia. Brain Res 148:264-268.

Gonzalez-Garcia M, Garcia I, Ding L, O’Shea S, Boise LH, Thompson CB, Nunez G (1995) bcl-x is expressed in embryonic and postnatal neural tissues and functions to prevent neuronal cell death. Proc Natl Acad Sci USA 92:4304-4308.

Gorin PD, Johnson Jr EM (1980) Effects of long-term nerve growth factor deprivation on the nervous system of the adult rat: an experimental autoimmune approach. Brain Res 198:27-42.

Greenlund LJ, Korsmeyer SJ, Johnson Jr EM (1995) Role of BCL-2 in the survival and function of developing and mature sympathetic neurons. Neuron 15:649-661.

Haldar S, Jena N, Croce CM (1995) Inactivation of Bcl-2 by phosphorylation. Proc Natl Acad Sci USA 92:4507-4511.

Ham J, Babij C, Whitfield J, Pfarr CM, Lallemand D, Yaniv M, Rubin LL (1995) A c-Jun dominant negative mutant protects sympathetic neurons against programmed cell death. Neuron 14:927-939.

Hopp TP, Prickett KS, Price VL, Libby RT, March CJ, Cerretti DP, Urdal DL, Conlon PJ (1988) A short polypeptide marker sequence useful for recombinant protein identification and purification. Biotechnology 6:1204-1210.

Hsu Y-T, Wolter KG, Youle RJ (1997) Cytosol-to-membrane redistribution of Bax and Bcl- $\mathrm{X}_{\mathrm{L}}$ during apoptosis. Proc Natl Acad Sci USA 94:3668-3672.

Ito T, Deng X, Carr B, May WS (1997) Bcl-2 phosphorylation required for anti-apoptosis function. J Biol Chem 272:11671-11673.

Johnson MI, Argiro V (1983) Techniques in the tissue culture of rat sympathetic neurons. Methods Enzymol 103:334-347.

Karin M (1995) The regulation of AP-1 activity by mitogen-activated protein kinases. J Biol Chem 270:16483-16486.

Karin M, Hunter T (1995) Transcriptional control by protein phosphorylation: signal transduction from cell surface to the nucleus. Curr Biol 5:747-757.

Koike T, Tanaka S (1991) Evidence that nerve growth factor dependence of sympathetic neurons for survival in vitro may be determined by levels of cytoplasmic free $\mathrm{Ca}^{2+}$. Proc Natl Acad Sci USA 88:3892-3896.

Lazarus KJ, Bradshaw RA, West NR, Bunge P (1976) Adaptive survival or rat sympathetic neurons cultured without supporting cells or exogenous nerve growth factor. Brain Res 113:159-164.

Levi-Montalcini R, Angeletti PU (1966) Immunosympathectomy. Pharmacol Rev 18:619-628.

Michaelidis TM, Sendtner M, Cooper JD, Airaksinen MS, Holtmann B, Meyer M, Thoenen H (1996) Inactivation of $b c l-2$ results in progressive degeneration of motoneurons, sympathetic and sensory neurons during early postnatal development. Neuron 17:75-89.

Miller TM, Johnson Jr EM (1996) Metabolic and genetic analyses of 
apoptosis in potassium/serum-deprived rat cerebellar granule cells. J Neurosci 16:7487-7495.

Miller TM, Moulder KL, Knudson CM, Creedon DJ, Deshmukh M, Korsmeyer SJ, Johnson Jr EM (1997) Bax deletion further orders the cell death pathway in cerebellar granule cells and suggests a caspaseindependent pathway to cell death. J Cell Biol 139:205-217.

Motoyama N, Wang F, Roth KA, Sawa H, Nakayama K, Nakayama K, Negishi I, Senju S, Zang Q, Fujii S, Loh DY (1995) Massive cell death of immature hematopoietic cells and neurons in Bcl-x-deficient mice. Science 267:1506-1510.

Oltvai ZN, Korsmeyer SJ (1994) Checkpoints of dueling dimers foil death wishes [comment]. Cell 79:189-192.

Otten U, Goedert M, Schwab M, Thibault J (1979) Immunization of adult rats against 2.5S NGF: effects on the peripheral sympathetic nervous system. Brain Res 176:79-90.

Ruit KG, Osborne PA, Schmidt RE, Johnson Jr EM, Snider WD (1990) Nerve growth factor regulates sympathetic ganglion cell morphology and survival in the adult mouse. J Neurosci 10:2412-2419.

Snider WD, Elliot JL, Yan Q (1992) Axotomy-induced neuronal death during development. J Neurobiol 23:1231-1246.

Vekrellis K, McCarthy MJ, Watson A, Whitfield J, Rubin LL, Ham J (1997) Bax promotes neuronal cell death and is downregulated during the development of the nervous system. Development 124:1239-1249.

Zha J, Harada H, Yang E, Jockel J, Korsmeyer SL (1996) Serine phosphorylation of death agonist BAD in response to survival factor results in binding to 14-3-3 not BCL- $\mathrm{X}_{\mathrm{L}}$. Cell 87:619-628. 